\title{
Hybrid treatment of supravalvular aortic stenosis and coronary ostial stenosis in familial hypercholesterolemia
}

\author{
İsmail Selçuk ${ }^{1}$, Murat Uğur ${ }^{1}$, İbrahim Alp¹, Veysel Temizkan¹, Arif Selçuk ${ }^{1}$, \\ Ertürk Yedekçi², Ahmet Turan Yılmaz ${ }^{1}$
}

\footnotetext{
1) Department of Cardiovascular Surgery, Sultan Abdulhamid Han Training and Research Hospital, MD., Istanbul, Turkey

2) Department of Anesthesiology, Gulhane Training and Research Hospital, Ankara, Turkey

3) Department of Cardiovascular Surgery, Sultan Abdulhamid Han Training and Research Hospital, Prof., MD., Istanbul, Turkey
}

\begin{abstract}
Familial hypercholesterolemia (FH) is an autosomal dominant inherited metabolic disorder characterized with high levels of low-density lipoprotein (LDL) plasma cholesterol. Increased plasma LDL-cholesterol levels cause cutaneous and tendinous xanthomas, supravalvular aortic stenosis and coronary ostial stenosis in younger ages. Complications can be fatal if it is not diagnosed and treated in preliminary stages. We present a 22 -year-old male patient with familial hypercholesterolemia and concomitant supravalvular aortic stenosis and coronary artery disease treated with hybrid coronary revascularization approach.
\end{abstract}

Key words: Familial Hypercholesterolemia, Coronary Ostial Stenosis, Supravalvular Aortic Stenosis, Hybrid Approach 


\section{Introduction}

Familial hypercholesterolemia (FH) is a metabolic disorder caused by the mutations in the low density lipoprotein (LDL) cholesterol receptor gene. ${ }^{1}$ The incidence of autosomal dominant inherited familial hypercholesterolemia is 1 in $1.000 .000{ }^{2,3}$ Hypercholesterolemia not only affects the aortic root but also the aortic valve. Plaques formed by the accumulation of cholesterol particles lead supravalvular aortic stenosis along with the atherosclerosis causing severe ostial stenosis of coronary arteries. ${ }^{4}$ Patients with this disorder might develop ischemic heart disease and myocardial infarction at early ages. In this case, we report a patient with autosomal dominant inherited familial hypercholesterolemia complicated with supravalvular aortic stenosis and coronary artery disease who was surgically treated with hybrid approach.

\section{Case Report}

A 22-year-old male patient was admitted to our department with symptoms of chest pain and dyspnea on exertion. He had been diagnosed with FH approximately 10 years ago. On admission he had xanthomas on his left elbow (Figure 1). He was a child of a consanguineous marriage. Although the use of HMG-CoA reductase inhibitor, laboratory studies of the patient, whose body surface area was $0.93 \mathrm{~m} 2$, showed elevated serum total cholesterol, LDL cholesterol, high density lipoprotein (HDL) cholesterol and triglyceride levels which were $560 \mathrm{mg} / \mathrm{dl}, 450 \mathrm{mg} / \mathrm{dl}, 41 \mathrm{mg} / \mathrm{dl}$ and $146 \mathrm{mg} / \mathrm{dl}$, respectively. Transthoracic echocardiography (TTE) showed combined supravalvular aortic stenosis (peak/average gradient: $53 / 28 \mathrm{mmHg}$ ) and moderate aortic valve insufficiency. Angiographic examination revealed severe stenosis in the proximal left main coronary artery

Figure 1. Xanthomas on the left elbow.

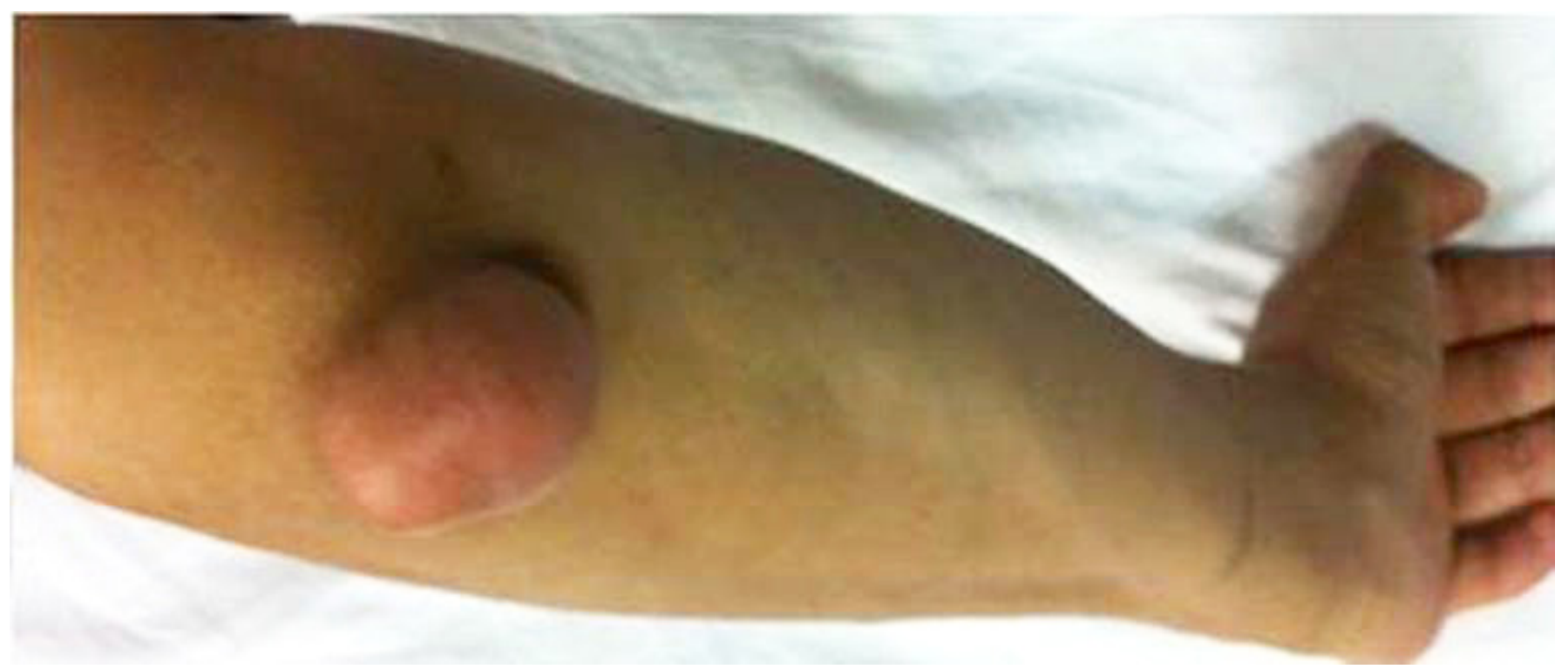

Figure $2.90 \%$ osteal stenosis of LMCA, b. Stenosis $(80 \%)$ in the mid portion of Cx artery.

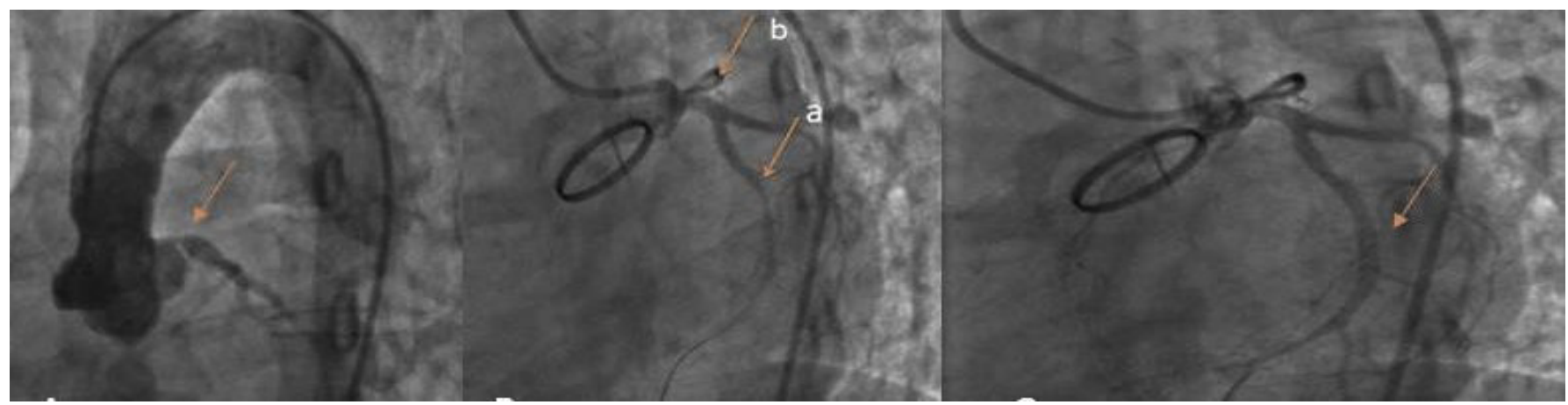


(LMCA) and in the body of circumflex (Cx) artery as well as supravalvular aortic stenosis. (Figure 2)

Decision of surgical intervention was made according to these medical findings. Supracoronary ascending aorta and aortic valve were resected. Aortic valve replacement was performed with $21 \mathrm{~mm}$ St. Jude HP prosthesis. Then, osteal stenosis of LMCA was repaired with pericardial patchplasty and the patch was extended through the sinus of Valsalva. This surgical technique made the left sinus of Valsalva larger. (Figure 3) Subsequently, ascending aorta was replaced with a $26 \mathrm{~mm}$ Dacron graft. After two weeks of uneventful postoperative period, the cardiologist placed two metal stents to the $\mathrm{Cx}$ artery at cardiology unit. The patient was dis-

Figure 3. BT angiographic view of LMCA ostium after osteal patchplasty.

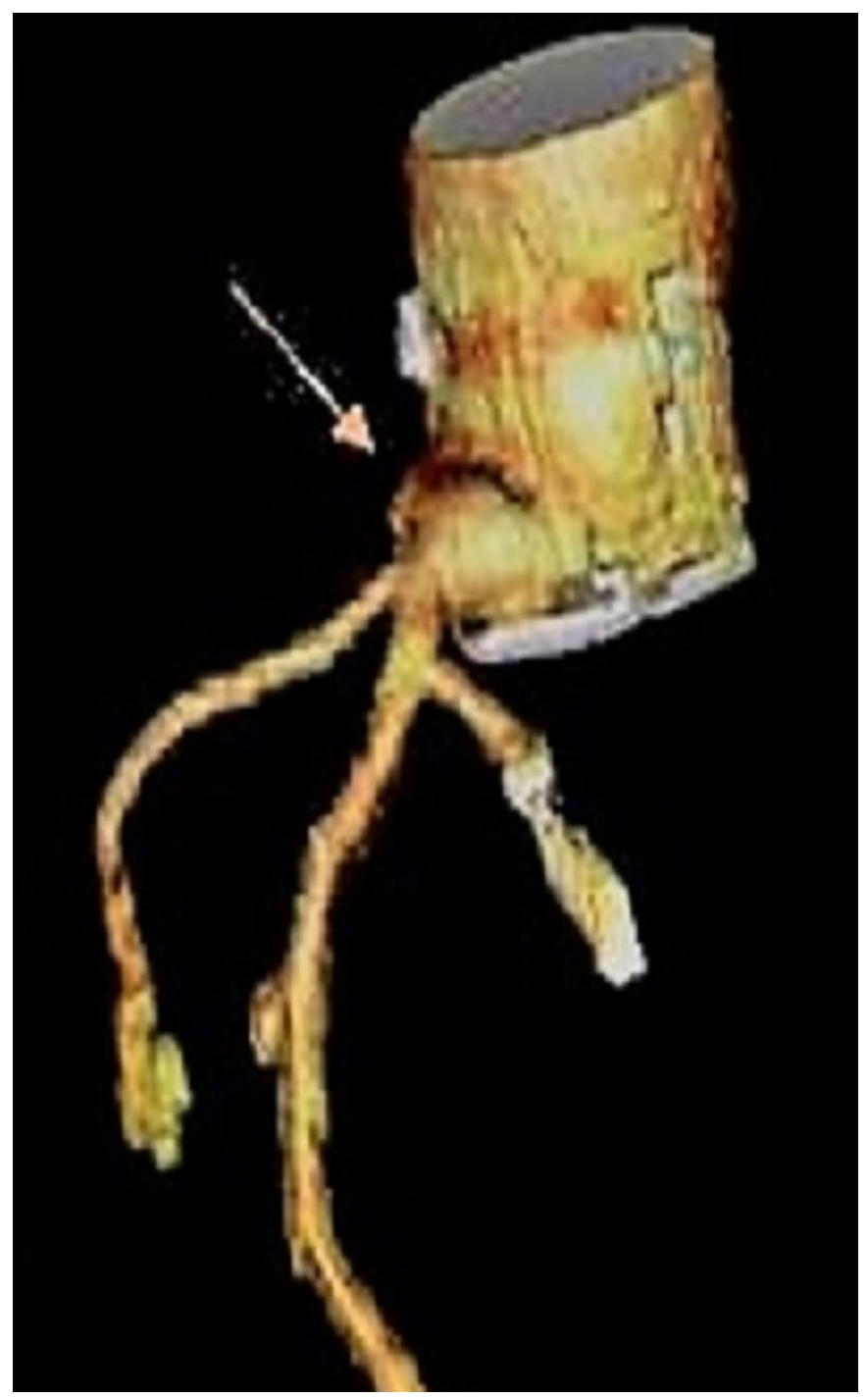

charged with anticoagulant, antiplatelet and statin therapies without any complications on the postoperative 16th day. The patient is in the follow-up period without any problem presently.

\section{Discussion}

Hyperlipidemia, premature atherosclerosis causing coronary artery disease, supravalvular aortic stenosis, large vessel atherosclerosis and giant xanthomas can be seen familial hypercholesterolemia. Atherosclerotic plaque of the aorta mostly develops in the abdominal segment in elderly patients, whereas premature atherosclerosis is often found in the ascending aorta and coronary ostia in patients with homozygous familial hypercholesterolemia. ${ }^{3,5}$ This condition leads to development of supravalvular aortic stenosis and ostial stenosis of the coronary arteries.

Treatment of homozygous FH consists of diet, medical therapy and apheresis. However, despite the medical treatment, majority of patients necessitate coronary revascularization and valve repair surgery. Coronary artery bypass grafting $(\mathrm{CABG})$ with a full arterial grafting is a surgical option with longer patency rates in younger patients. ${ }^{6}$ In selected left main coronary artery lesions (noncalcified isolated lesions of the proximal or midportion LMCA) surgical patch angioplasty might be an alternative to $\mathrm{CABG}$.

Surgical patchplasty restores patency of the narrowed coronary artery segment and increases physiological antegrade coronary artery blood flow. In LMCA lesions, if the coronary arteries are buried intramyocardially, the surgical patch angioplasty may be the only viable surgical treatment. If we use LMCA patchplasty in younger ages, classical CABG surgery and percutaneous stent implantation are available for distal coronary artery disease that might come out in future. Also, in case of a reoperation, the anatomy of the coronary graft is prevented from deterioration.

Autologous pericardium and saphenous vein are the most preferred patch materials with sufficient width and ease to suture. Malyshev et al. reported the rate of restenosis for autologous venous material and autologous pericardium were $3.4 \%$ and $4.9 \%$, respectively. ${ }^{7}$ In our patient a young patient has osteal stenosis of LMCA and 
stenosis of the Cx artery at the atrioventricular grove. In classic hybrid approach, minimal invasive LIMA to LAD bypass graft and percutaneous coronary intervention through to remaining lesions can be preferred. ${ }^{8}$ In our patient, we provided anatomical coronary ostial patency with patchplasty and hybrid coronary revascularization to the $\mathrm{Cx}$ artery in case of a need to a reoperation in the future.

Close follow-up is important in patients with familial hypercholesterolemia since ostial coronary artery

\section{References}

1. Kawasuji M, Sakakibara N, Takemura H, Matsumoto Y, Mabuchi H, Watanabe Y. Coronary artery bypass grafting in familial hypercholesterolemia. J Thorac Cardiovasc Surg. 1995;109:364-369

2. Qaiser S, Sheikh S, Malik MS. Homozygous Familial Hypercholestrolaemia presents with supravalvular aortic stenosis, J Pak Med Assoc. 2012;62:612-614

3. Srimannarayana I, Varma RS, Satheesh S, Anilkumar R, Balachander J. Supravalvular Aortic Stenosis and Coronary Ostial Stenosis in Homozygous Familial Hypercholesterolemia. Indian Heart J. 2004;56:152-154

4. Rallidis L, Naoumova RP, Thompson GR, Nihoyannopoulos P. Extent and severity of atherosclerotic involvement of the aortic valve and root in familial hypercholesterolaemia. Heart. 1998;80:583-590

5. Beppu S, Minura Y, Sakakibara H, Nagata S, Park YD, Nambu S, Yama- disease and ascending aorta disease with valvular involvement are likely to be seen at early ages of life. In LMCA lesions accompanying supravalvular aortic stenosis, ostial patchplasty combined with percutaneous coronary revascularization seems a better treatment option (especially in young patients) compared with conventional $\mathrm{CABG}$, as there is no graft problem in redo surgery, the coronary anatomic plane is preserved and the higher capability of percutaneous interventions in concomitant distal coronary lesions. moto A. Supravalvular aortic stenosis and coronary ostial stenosis in familial hypercholesterolemia: two-dimensional echocardiographic assessment. Circulation. 1983;67:878-884

6. Nemati MH, Astaneh B, Joubeh A. Triple coronary artery bypass graft in a 10-year-old child with familial hypercholesterolemia. Gen Thorac Cardiovasc Surg 2009 57:94-97

7. Malyshev M, Gladyshev I, Safuanov A, Siniukov D, Borovikov D, Rostovykh N. Surgical angioplasty of the left main coronary artery and/or proximal segment of the right coronary artery by pulmonary autograft patch. Eur J Cardiothorac Surg. 2004;25:21-25

8. Verhaegh AJ, Accord RE, van Garsse L, Maessen JG. Hybrid coronary revascularization as a safe, feasible, and viable alternative to conventional coronary artery bypass grafting: What is the current evidence? Minim Invasive Surg. 2013;142616.
Received: $27 / 02 / 2018$

Accepted: 28/05/2018

Published: 01/06/2018

Disclosure and conflicts of interest:

The authors declare no conflict of interest.

\section{Corresponding author:}

Murat Uğur

Mail: drmugur@gmail.com 